NBER WORKING PAPER SERIES

\title{
DECOMPOSING THE PERSISTENCE OF INTERNATIONAL EQUITY FLOWS
}

\author{
Kenneth A. Froot \\ Jessica D. Tjornhom \\ Working Paper 9079 \\ http://www.nber.org/papers/w9079 \\ NATIONAL BUREAU OF ECONOMIC RESEARCH \\ 1050 Massachusetts Avenue \\ Cambridge, MA 02138 \\ July 2002
}

We are grateful to State Street Corporation for help in obtaining data and to Gang Bai for extraordinarily effective research assistance. The views expressed herein are those of the authors and not necessarily those of the National Bureau of Economic Research.

(C) 2002 by Kenneth A. Froot and Jessica D. Tjornhom. All rights reserved. Short sections of text, not to exceed two paragraphs, may be quoted without explicit permission provided that full credit, including (C) notice, is given to the source. 
Decomposing the Persistence of International Equity Flows

Kenneth A. Froot and Jessica D. Tjornhom

NBER Working Paper No. 9079

July 2002

JEL No. G15, F21, G11

\begin{abstract}
$\underline{\text { ABSTRACT }}$
The portfolio flows of institutional investors are widely known to be persistent. What is less well known, however, is the source of this persistence. One possibility is the ?informed trading hypothesis?: that persistence arises from autocorrelated trades of investors who believe they have information about value and who face an imperfectly liquid market. Another possibility is that there are asynchroneities with respect to investment decisions across funds, across investments, or both. These asynchroneities could be due to wealth effects (across investments for a single fund), investor herding (across funds for a single investment), or generalized contagion (across funds and across investments). We use daily data on institutional flows into 21 developed countries by 471 funds to measure and decompose aggregate flow persistence. We find that the informed trading hypothesis explains about $75 \%$ of total persistence, and that the remaining amount is attributable entirely to cross-fund own-country persistence. In other words, we find statistically and economically significant flow asynchroneities across funds investing in the same country. There are no meaningful asynchroneities across countries, either within a given fund, or across funds. The cross-fund flow lags we identify might result from different fund investment processes, or from some funds mimicking others? decisions. We reject the hypothesis that wealth effects explain persistence.
\end{abstract}

Kenneth A. Froot

Graduate School of Business

Harvard University

Soldiers Field

Boston, MA 02163

and NBER

kfroot@hbs.edu
Jessica D. Tjornhom

State Street Associates

jdtjornhom@statestreet.com 


\section{Introduction}

If there were a single characteristic that describes the portfolio flows of institutional investors, it would seem to be flow persistence. A number of authors in widely varying contexts have found this result. Studies looking at individual Asian equity markets have found that foreigner's flows are strongly persistent (see for example, Choe, Kho, and Stulz $(1999,2001)$ and Kim and Wei (2001) who focus on Korean flows and Seasholes (2001) who has focused on the Thai and Taiwanese equity markets). Studies of institutional investor flows across a number of markets have also found strong persistence on country or regional levels (see Richards (2002), Froot, O'Connell, and Seasholes (2001), Froot and Ramadorai (2002) and Kaminsky, Lyons, and Schmukler (2000)). In addition, studies of mutual fund flows in the US show persistence at relatively high frequencies. These empirical findings are robust, not only across different databases, but also after conditioning on other variables. For example, a number of the above studies demonstrate that flow persistence does not appear strongly diminished by controlling for past returns, even though past returns and past flows are correlated.

Persistence in net purchases by institutional investors would not seem very important if institutional flows had no stable relationship with prices. However, this is not the case. Considerable research has documented that current returns are strongly positively correlated with institutional flows, that current institutional flows tend to react positively to past returns, and that current flows are positively predictive of future returns. These associations suggest that institutional flows may be bound up with return momentum in equities, which is, to date, one of the broadest and most prevalent empirical anomalies in asset pricing. ${ }^{1}$

While persistence in institutional flow is clear in the data, the underlying mechanisms driving it are not. In models of informed trading (such as Kyle 1985), informed order flow is conditionally autocorrelated. Traders with positive information attempt to disguise it, rationing their purchases at any given time and deferring some into the future, in order to reduce total price impact. The

\footnotetext{
${ }^{1}$ On the profitability and breadth of moment effects see Jegadeesh and Titman (1993) and Rouwenhorst (1988). A number of papers study the relationship between institutional flows and equity returns both in the US and internationally. See Cohen, Gompers, and Vuolteenaho (2001), Froot, O'Connell, and Seasholes (2001), Froot and Ramadorai (2001), Grinblatt and Keloharju, (2000), Grinblatt, Titman, and Wermers (1995), Lakonishok, Shleifer, and Vishny (1992), Nofsinger and Sias (1999), Richards (2002), Wermers $(1999,2000)$.
} 
same holds if the information is merely perceived, rather than actual, i.e., if there is trader overconfidence.

This type of mechanism suggests that the persistence in institutional order flow is related to the scope of (real or perceived) information. Under what we call the informed trading hypothesis, each fund's purchases of a given country's equities are likely to be own-autocorrelated, provided that the funds learn about the prospects of firms within that country. The autocorrelation emerges because individual fund managers have either company-specific or country-specific information and dispense it slowly and optimally into prices.

However, such own-fund own-country persistence is likely to be only one piece of the total persistence in aggregated flow data. First and most obviously is that this effect may occur across several countries at once. If two managers learn about the same country at the same time, for example, each spacing over time their trades, then there will be cross-fund, own-country persistence. This will result simply from each manager following the optimal trading strategy over time for each country. Alternatively, if managers learn about two countries at once, for example, again spacing over time their trades in each country, then there will be own-fund, crosscountry persistence. And finally, if two managers each learn about two countries at the same time and space their trades according to Kyle, then there will also be cross-fund, cross-country persistence. All these forms of persistence occur under the informed trading hypothesis.

Of course, mechanisms other than this dynamic optimal trading hypothesis may be at work. The most general alternative explanation is lack of simultaneity. Investors may process information or come to opinions at different rates, wait for other confirmatory signals for different amounts of time, etc. These delays induce cross-fund and cross-country persistence, over and above any own-fund own-country persistence. Such lack of simultaneity may arise from many different sources. One is that there may be lags associated with infrastructure, bureaucracy, or decisionmaking. These lags may operate across investments within a single fund or across funds. For example, shocks to fund wealth may result in rebalancing transactions that take time to complete (for a model along these lines, see Kyle and Xoing, 2001). Another source of asynchronicity is that managers respond positively to each other's decisions with some lag. Such responses might be construed as a form of investor herding. The cause of the herding could be quite rational. Fund managers might find that they increase returns by following first movers. Or they might find that following first movers reduces tracking error against a peer benchmark. 
These alternative mechanisms induce persistence in aggregated flows even in the absence of ownfund own-country persistence due to the informed trading hypothesis. Clearly, these mechanisms would need to be better understood if they are important components of persistence. This is especially true if they are present after own-fund, own-country persistence - and therefore the Kyle story - is controlled for in the data.

The purpose of this paper is to decompose persistence in institutional investor flow across funds and countries. We measure this decomposition and use it to test for deviations from the informed trading hypothesis. These deviations can provide considerable information on the mechanisms behind flow persistence. A good analogy to what we do comes from the literature decomposing the persistence of equity index returns. There, return aggregates are also positively autocorrelated. As that work showed, virtually all of the autocorrelation of historical US equity indexes is attributable to non-contemporaneous cross-stock return correlations; own-stock autocorrelations are zero. While the literature has not arrived at a definitive model of the leads and lags of individual stocks versus the index, the decomposition is crucial in attempts to test different theories (e.g., non-trading, short sales constraints, informational inefficiencies, etc.) Our problem in flows is considerably richer, since in addition to the cross-country dimension we have an added cross-fund dimension. ${ }^{2}$

To preview our results, we perform a naïve decomposition of flow persistence and find, as expected, that own-fund own-country persistence is not very important. Own-fund own-country persistence explains about $10 \%$ of total persistence, with the rest coming from cross effects. This is not very surprising given the sheer size of our cross section (471 funds $\mathrm{x} 21$ countries). Most important would appear to be the cross-fund cross-country component, which is the most important cross-sectional dimension.

We find a very different picture, however, when we condition persistence on the size of the ownfund own-country persistence. We ask whether the cross components are large given the magnitude of observed own-fund own-country persistence. The answer for the cross-country components appears to be 'no:' cross-country components are about exactly as large as we would expect them to be under the informed trading hypothesis. However, the answer for the cross-fund

\footnotetext{
${ }^{2}$ See, for example, Lo and MacKinley (1995) and Froot and Perold (1995).
} 
own-country component is 'yes:' this piece is bigger than the informed-trader hypothesis would predict. There is 'excess' cross-fund persistence in the data. Indeed, we find that the 'excess' persistence accounts for about $25 \%$ of the total.

It turns out that virtually all of this excess persistence comes from the cross-fund own-country component. Across countries, both within and across funds, the persistence lines up with the informed-trading hypothesis. We therefore reject the informed trading null in favor of the alternative that there is a slow rippling of flow across funds for a given country, but not within a fund or across funds across countries. Thus, we find no evidence to support the Kyle and Xiong (2001) hypothesis that wealth effects within a fund result in cross-country noncontemporaneously correlated flows (sometimes invoked to explain 'contagion').

What might account for our findings of own-country cross-fund persistence? Two stories strike us as quite plausible. The first is that there are meaningful implementation and decision-making lags across funds. Information may reach these funds at the same time, but those who act upon it do not do so simultaneously. Another plausible story is there is a non-contemporaneous herding of funds with respect to country investments. After one fund's active reaction to new information, another fund may deliberately follow. It may be that one fund is trying to earn return by free-riding off another's value-added decisions with a lag. Or it may be that the second fund sees the first's decision as a change in its peer-driven benchmark. Either way cross-fund own-country persistence is important.

Empirically, our findings appear quite robust. With over 12 million fund/country/day flow data points, statistical power is not really an issue; all of the above rejections of the null are very highly statistically significant, while the failures to reject reflect extremely (economically) small point estimates. Second, the results are essentially unchanged whether persistence is measured in daily or weekly data. Third, is no impact on the results of conditioning on other variables that have been identified as important short run determinants of flows, such as lagged returns. And finally, there is only small difference in the estimates for emerging versus developed markets: emerging markets feature slightly higher levels of persistence, but a very similar decomposition nevertheless. 
The rest of the paper is structured as follows. Section II discusses the decomposition. Section III describes the data. Section IV provides some basic descriptive statistics. Section V discusses the main results and Section VI concludes. 


\section{Decomposition}

We begin with the established fact, and one that we further confirm in our data: that institutional order flow aggregated across funds and countries is highly autocorrelated:

$$
f_{t}=\delta+\alpha f_{t-\tau}+\varepsilon_{t}
$$

where flow is aggregated across funds $(i=1, \ldots, l)$ and countries $(k=1, \ldots K), f_{t}=\sum_{i} \sum_{k} f_{i, k, t}$. With respect to normalization of the flows, there is no clearly dominant solution.

One approach, used commonly, is to normalize the underlying value of flow by country market capitalization as a way of controlling for differences in market capacity, i.e., $f_{i, k, t}=\frac{F_{i, k, t}}{M_{k, t-1}}$, where $F_{i, k, t}$ is the dollar amount of net flow into country $k$ by fund $i$, summed across all transactions on date $t$, and $M_{k, t}$ is the dollar market capitalization of the $k$ th country.

Clearly, this normalization does not condition on fund size at all. This is typical in that previous papers have simply used aggregated dollar amounts across managers. However, with our disaggregated data, we have the flexibility to weight flow differently. One simple approach that puts different markets and funds on a more similar footing is a digital normalization. It treats all fund/countries with net buys (sells) on a given day as having the same as the same flow magnitude, i.e., $f_{i, k, t}^{d}=\operatorname{sign}\left(\frac{F_{i, k, t}}{M_{k, t-1}}\right)$, where $\operatorname{sign}($.$) returns either 1,0$, or -1 .

A second approach to normalization uses the net buy count for each fund/country/date. Letting $B_{i, k, t}$ and $S_{i, k, t}$ represent the number of buys and sell, respectively for each fund/country/date, we define a flow count normalization to be $f_{i, k, t}^{c}=\frac{B_{i, k, t}-S_{i, k, t}}{B_{i, k, t}+S_{i, k, t}}$.

In much of what follows, we rely on $f_{i, k, t}^{d}$ and $f_{i, k, t}^{c}$, since these are comparably scaled across both funds and countries. 
Once we have chosen a particular normalization, we next need to characterize the sources of persistence. This is becomes a four-dimensional problem if we want to characterize generally the noncontemporaneous cross correlation between $f_{i, k, t}$ and $f_{j, l, t-\tau}$. To be specific, the $\tau$ th-order normalized cross covariance is given by $\rho_{i, k, j, l}^{\tau}=\frac{\operatorname{cov}\left(f_{i, k, t}, f_{j, l, t-\tau}\right)}{\operatorname{var}\left(f_{t}\right)}$, and the corresponding covariance matrix by $\Gamma(1)$. The $\tau$ th-order autoregressive coefficient of total flow above, $\alpha(\tau)$, is given by: ${ }^{3}$

$$
\alpha(\tau)=\sum_{i} \sum_{j} \sum_{k} \sum_{l} \frac{\operatorname{cov}\left(f_{i, k, t}, f_{j, l, t-\tau}\right)}{\operatorname{var}\left(f_{t}\right)}
$$

In order to make some headway here in reducing the dimensionality of the problem, we divide up these terms. We can afford to do this: since we employ data on 471 funds and 21 countries, $\Gamma(\tau)$ has over 97 million elements for a single lag, $\tau$.

We therefore divide things using the simple distinction between own versus cross correlations in each dimension. This brings us down to just 4 components, two in each dimension. Specifically, we group the $\Gamma(\tau)$ matrix as (this is depicted visually in Figure 1 below):

$$
\begin{aligned}
\alpha(\tau)= & \sum_{k} \sum_{i}\left(\frac{\operatorname{cov}\left(f_{i, k, t}, f_{i, k, t-\tau}\right)}{\operatorname{var}\left(f_{t}\right)}+\sum_{j \neq i} \frac{\operatorname{cov}\left(f_{i, k, t}, f_{j, k, t-\tau}\right)}{\operatorname{var}\left(f_{t}\right)}\right. \\
& \left.+\sum_{l \neq k} \frac{\operatorname{cov}\left(f_{i, k, t}, f_{i, l, t-\tau}\right)}{\operatorname{var}\left(f_{t}\right)}+\sum_{j \neq i} \sum_{l \neq k} \frac{\operatorname{cov}\left(f_{i, k, t}, f_{j, l, t-\tau}\right)}{\operatorname{var}\left(f_{t}\right)}\right)
\end{aligned}
$$

To save space, assume that each of the covariances above is constant, so that we can estimate a single parameter for each. That is, we impose the following 4 restrictions, each corresponding to a specific type of covariation.

1. Equal Own-fund own-country covariations:

\footnotetext{
${ }^{3}$ Partial $\tau^{\text {th }}$-order coefficients use only the portion of $f_{i, k, t}$ that is orthogonal to the prior $\tau-1$ lags.
} 


$$
\frac{\operatorname{cov}\left(f_{i, k, t}, f_{i, k, t-\tau}\right)}{\operatorname{var}\left(f_{t}\right)}=\alpha_{\mathrm{oo}}(\tau) \text { for all } i, k \text { pairs. }
$$

This can be seen in Figure 1 as the main diagonal of the covariance matrix. Own-fund, owncountry persistence is probably easiest to interpret. It comes from persistence in each fund's purchases of a country's equities. For example, Japanese equity inflows may be persistent because a given fund's purchases of Japanese equities today will on average continue for several days. Own-fund own-country persistence is what we would expect from an informed investor in the Kyle (1985) model. It is also what we would expect from an overconfident investor, who behaves as though he has information. ${ }^{4}$

\section{Equal cross-fund own-country covariations:}

$$
\sum_{j \neq i} \frac{\operatorname{cov}\left(f_{i, k, t}, f_{j, k, t-\tau}\right)}{\operatorname{var}\left(f_{t}\right)}=\alpha_{\mathrm{co}}(\tau) \text { for all } i \neq j, \text { and for all } k
$$

This source of persistence can be seen as the triangles along the main diagonal of Figure 1. This component is driven by non-synchronized purchases across funds of the same country's equities. For example, suppose a given fund buys Japanese equities today. While that fund may not on average purchase more Japanese equities tomorrow (i.e., $\alpha_{\mathrm{oo}}(\tau)=0$ ), other funds may tend to purchase Japanese equities at that time. The information or opinion that causes one fund to trade Japanese equities may ripple out across funds over time, creating persistence in Japanese flows. We call this cross-fund own-country persistence.

This source of cross-persistence is analogous in many ways with the source of cross-persistence that has been observed in equity index returns. Of course, cross-fund persistence is likely to be far richer than own-fund persistence, especially when there is a relatively large cross section of funds. To continue the analogy with stock returns, cross-persistence arises partly from returns on large firms predicting returns on small firms. This effect becomes more intensive within a given industry. Similar patterns are likely to be operative across funds. As groups, passive index funds versus active funds are not likely to demonstrate much cross-fund persistence. Such cross-

\footnotetext{
${ }^{4}$ We do not test in this paper the information content of institutional investor trades, so we are agnostic here about whether persistent trades are the result of information or overconfidence.
} 
persistence is likely to be much more important within each group of funds rather than across the groups.

As a first step, we impose the restriction in 2 above, estimating the average off-diagonal covariance.

3. Equal own-fund cross-country covariations

$$
\sum_{l \neq k} \frac{\operatorname{cov}\left(f_{i, k, t}, f_{i, l, t-\tau}\right)}{\operatorname{var}\left(f_{t}\right)}=\alpha_{\mathrm{oc}}(\tau) \text { for all } k \neq l, \text { and for all } i
$$

Figure 1 shows own-fund cross-country covariances as the minor diagonal lines. Flows into a given country from a given fund may be correlated with past flows into other countries from the same fund. A fund buying Japanese equities today might buy Australian equities tomorrow. Reasons for this source of persistence include a substitution effect towards Australian equities as Japanese equity prices rise, an implementation lag in getting to Australian equities, an emerging appreciation that the news for Japan also may apply to Australia, etc. In addition, own-fund cross-country covariation may occur in the context of strong own-fund own-country correlation. If purchases of both Japanese and Australian equities show strong own persistence, then purchases of both markets initiated at similar times will also generate own-fund, cross-country covariation.

\section{Equal cross-fund cross-country covariations}

$$
\sum_{j \neq i} \sum_{l \neq k} \frac{\operatorname{cov}\left(f_{i, k, t}, f_{j, l, t-\tau}\right)}{\operatorname{var}\left(f_{t}\right)}=\alpha_{\mathrm{cc}}(\tau) \text { for all } i \neq j, \text { and } k \neq l \text {. }
$$

Figure 1 shows cross-fund cross-country covariances as the triangles surrounding the minor offdiagonal lines. This is the most dispersed form of persistence. Purchases of a given country by one fund may over time diffuse toward purchases by other funds of other countries.

Together, these four restrictions can be used to decompose the aggregate autocorrelation of total flows, shown in equations (1) and (2): 


$$
\alpha(\tau)=I K\left(\alpha_{o o}(\tau)+\alpha_{c o}(\tau)+\alpha_{o c}(\tau)+\alpha_{c c}(\tau)\right)
$$

These four components of $\alpha$ can be estimated using OLS in the individual regressions

$$
f_{i, k, t}=c+a(L) x+\varepsilon_{t}
$$

where $a(L)$ takes on the values, $\alpha_{o o}(\tau), \alpha_{o c}(\tau), \alpha_{c o}(\tau)$, and $\alpha_{c c}(\tau)$, when $x$ takes on the values

$$
\begin{gathered}
c_{o o} f_{j, k, t-\tau}, \\
c_{o c} \sum_{j \neq i} f_{j, k, t-\tau}, \\
c_{c o} \sum_{l \neq k} f_{i, l, t-\tau}, \\
\text { and } c_{c c} \sum_{j \neq i} \sum_{l \neq k} f_{j, l, t-\tau},
\end{gathered}
$$

respectively, and where the $c$ 's are constants of proportionality such that in all four cases the standard deviation of $x$ equals that of aggregate flow, $f_{t}$.

\section{II.A Is flow persistence driven entirely by informed or overconfident trading?}

This decomposition provides perspective on the magnitude of the individual own- and crosseffects driving aggregate flow persistence. We need to go an additional step, however. The informed/overconfident trader hypothesis that we discuss above suggests that own-purchases are serially correlated. Traders get slowly into positions and the magnitude of their trades is a function to the perceived difference between value and price. In the continuous auction environment of Kyle (1985), market depth (i.e., the sensitivity of price to incremental order flow) is constant. In expectation, as the informed trader pushes price towards perceived value, trade size declines. In this sense flow is stationary and persistent with respect to shocks to perceived value.

If we take the informed trader story as our null hypothesis, we would predict that cross-country and cross-fund persistence emerge as a result. These additional sources of persistence emerge 
because perceived opportunities may be contemporaneously correlated across countries. In the presence of own-fund own-country persistence, contemporaneous correlation across funds and countries will translate into non-contemporaneous correlation.

To see this, take the simple case in which flows for a given fund / country are autoregressive and stationary, and have iid news (or overconfidence) shocks:

$$
f_{i, k, t}=\theta_{i, k}(L) f_{i, k, t-1}+\xi_{i, k, t}
$$

where $L$ is the lag operator. Given stationarity, it follows that $f_{i, k, t}$ can be written as a moving average process, $f_{i, k, t}=\phi_{i, k}(L) \xi_{i, k, t}$, where $\phi_{i, k}(L)=\left(1-\theta_{i, k}(L)\right)^{-1}$. Even though the $\xi$ shocks are serially uncorrelated across all funds and countries ( $i$ and $k$ ), they may be contemporaneously correlated across both funds and countries. As a result, even small amounts of contemporaneous correlation between $\xi_{i, k, t}$ and $\xi_{j, l, t}$ can generate important non-contemporaneous cross-country and/or cross-fund correlations between $f_{i, k, t}$ and $f_{j, l, t-\tau}$ under the informed/overconfident trader hypothesis.

Notice, however, that if we can control properly for the own-autoregressive correlations in $f_{i, k, t}$, then the remaining own-flow components will be uncorrelated across funds, countries, and time. That is, after controlling for the own-autoregressive part of $f_{i, k, t}$, we are left with $\xi_{i, k, t}$. These own-flow innovations are uncorrelated with past own- and cross-flow innovations. That is, $\xi_{i, k, t}$ is uncorrelated with $\xi_{j, l, t-\tau}$, for all values of $i, j, k, l$, and $\tau>0$.

Consider, then the regression:

$$
f_{i, k, t}=c+a_{o o}(L) f_{i, k, t-1}+\frac{a_{c o}(L)}{I-1} \sum_{j \neq i} f_{j, k, t-1}+\frac{a_{o c}(L)}{K-1} \sum_{l \neq k} f_{i, l, t-1}+\frac{a_{c c}(L)}{(I-1)(K-1)} \sum_{j \neq i} \sum_{l \neq k} f_{j, l, t-1}+\varepsilon_{i, k, t}
$$

where we have made the coefficients easier to compare with one another by dividing by the number of funds and countries over which we sum (i.e., by $(I-1)$ and $(K-1)$, respectively). This 
specification sops up the own-flow own-country persistence and tells us the size and significance of average measures of cross flows. Thus, the informed trader hypothesis suggests that the ownfund own-country coefficient is positive, $a_{o o}(L)>0$, and that the cross coefficients are zero, $a_{c o}(L)=a_{o c}(L)=a_{c c}(L)=0$. Our alternative hypotheses are that one or more of these latter coefficients are different from zero. These coefficients represent the extent to which there is excess covariation in flows across funds and countries. Essentially, if these latter coefficients are different from zero, then there must be some other source of flow correlation beyond the attempt to hide perceived information from the market.

For example, suppose that $a_{c o}(L)>0$, so there is excess cross-fund, own-country persistence. This suggests that some funds react to the same news as other funds with a lag in terms of investing in country $k$. As mentioned above, this lag may be driven by implementation and decision-making lags and delays. Examples range from the trader being out sick on the day news arrives, to a slower system of identifying stocks, to a desire for additional confirmatory information that arrives only with a lag (e.g., being able to observe the trades of peer funds).

Alternatively, suppose that $a_{o c}(L)>0$, which corresponds to excess own-fund, cross-country persistence. This suggests that there are delayed reactions across country investments within a fund. Here, peer and herding explanations of the lags are not appropriate. The only sensible source would seem to be implementation lags and delays.

Finally, consider the possibility that $a_{c c}(L)>0$, so that there is excess cross-fund, cross-country persistence. Here the same implementation lags are a possible underlying cause, though here they are cross-fund and cross-country (e.g.,. fund 2 investing in Spain with a lag behind fund 1's investment in Italy). Peer and herding issues may also be important here, to the extent they span investment opportunities other than countries. For example, suppose that funds focus on diversifying across corporate sectors, rather than countries. Then cross-fund delays in investing (due to either implementation issues or peer concerns) would necessarily show up as crosscountry delays as well. ${ }^{5}$

\footnotetext{
${ }^{5}$ There is increasing evidence that sector allocations are as important, or even more important than country allocations for diversifying risk. See, for example, VanRoyen and Page (2002).
} 
Note that the specification in equation (6) may be overly restrictive in several ways. First, it assumes own-fund own-country persistence profiles are the same across all countries. This may not be the case. For example, in markets with greater amounts of liquidity (i.e., uninformed order flow), the persistence of informed trading may be less, since the price impact of flow in such markets is likely to be lower.

As a result, it may be useful to allow $a_{o o}$ to vary with $k$, in case there are important differences in own-fund, own-country persistence. Thus, we also estimate:

$$
f_{i, k, t}=c+a_{o o: k}(L) f_{i, k, t-1}+\frac{a_{c o}(L)}{I-1} \sum_{j \neq i} f_{j, k, t-1}+\frac{a_{o c}(L)}{K-1} \sum_{l \neq k} f_{i, l, t-1}+\frac{a_{c c}(L)}{(I-1)(K-1)} \sum_{j \neq i} \sum_{l \neq k} f_{j, l, t-1}+\varepsilon_{i, k, t}
$$

which is the same specification, except that it also includes separate own-fund own-country autoregressive coefficients for each market, $k, a_{o o ; k}$.

Second, to keep things simple, we have so far restricted the impact of past returns to be zero. It may make sense to measure flow persistence over and above any tendency for flows to chase past returns. This is an approach a number of authors have taken, and, indeed, past returns seem to be statistically significant (though not economically large) in explaining flows. In addition, under our informed trader null hypothesis, past own-country returns should be positively correlated with informed flows. We add both own-country returns and US returns, as there is considerable evidence in Richards (2002) that US returns positively forecast foreign country inflows. ${ }^{6}$

\section{Data}

The flow data used in our analysis are derived from proprietary data provided by State Street Corporation. State Street is one of the world's largest global custodians, with approximately $\$ 7$ trillion of assets under custody. We extract data for a set of 930 distinct funds (without names or identifying characteristics to protect anonymity) from a total of almost 10,000 funds, using the criteria that a fund must trade equities incorporated in 21 or more distinct countries. Because our focus is on active, not passive funds, we reduce the set of funds by choosing only those that,

\footnotetext{
${ }^{6}$ See papers by Froot, O'Connell, Seasholes (2001), Richards (2002) and Stulz et al and the references therein.
} 
when they are active in the dataset, trade at least $75 \%$ of the days during their active period. We focus on a set of 21 developed markets leaving us a sample of 471 funds.

Our country designations are somewhat unusual, in that they are driven by an equity issuer's country of incorporation. This definition allows us to include the trading ADRs and GDRs, categorized according to the company's country of incorporation, rather than according to where the security is traded. We focus on the 21 developed countries based on the number of transactions that exist in the reduced dataset. ${ }^{7}$ The set of countries includes Australia, Austria, Belgium, Canada, Denmark, Finland, France, Germany, Greece, Ireland, Italy, Japan, New Zealand, Netherlands, Norway, Portugal, Spain, Sweden, Switzerland, United Kingdom, and the United States. With 2,166 days in the sample since 1994, our ultimate data set has over 12 million observations of net flows on a given day, into a given country, by a given fund.

In addition to the flow data, we also employ equity market returns. Returns are calculated using MSCI equity indices for each country used in our sample.

\section{Descriptive Statistics}

In this section we provide some background evidence on how the flow data behave. First, it is useful to get a sense for coverage. Figure 2 depicts the trading by individual funds by sample period dates, where the funds are aligned by first trading date. A date / fund element has no color if there were no trades by that fund on that day across all 21 countries. Note that trades are noticeably less frequent in the early part of the sample. Notice also that there are certain dates during the year when trading is light. The regular vertical lines in the graph correspond to the western Christmas and New Year's holidays. There also appears to be a dearth in trading during August 2000. Some of this may be anomalous to the dataset as there is no evidence that aggregate reported trading volumes fell unusually during that time.

Figure 3 provides a 'heatmap' showing fund trading by country. It shows the number of trades for each fund / country over the sample period, relative to the maximum number of trades for that fund in any country over the sample across all countries. It is clear that the major developed

\footnotetext{
${ }^{7}$ If there were less than a total of 2,000 transactions for a given country of incorporation using the original set of 930 funds, it was dropped from our data.
} 
countries account for a large percentage of the trading. Several developed countries, however, have very sparse transactions, including Belgium and Denmark. ${ }^{8}$

Figures 4 and 5 provide heatmaps of contemporaneous correlations of weekly cross-country and cross-regional flows. It is clear that there is strong positive correlation in flows across regions although there are a few regions negatively correlated such as Other Europe and Australia/New Zealand. As might be expected, the correlations of our 21 individual country flows are noisier. The preponderance of the coefficients is positive, but there are numerous correlations that are negative as well. Countries that are geographically closer seem to have higher correlations, as expected.

Table 1 reports some descriptive statistics for our net flow measures: dollar flows; digital indicator flows ( 1 for inflow, 0 for no flow, -1 for outflow); and buy-ratio flows (count of buys less sells normalized by buys plus sells). There are several points worth making.

First, the mean net flow by a single fund into a single country on a single day is just over $\$ 6,400$. Naturally, because this is a net flow, it is near zero. The daily standard deviation of own-fund own-country flows is much larger, approximately $\$ 1,198,840$. The mean net inflow while small is nevertheless highly statistically significant. Thus, during our period, there are net mean inflows recorded in our data; domestics on average are selling to international investors around the world.

Second, flows as expected are persistent, as suggested by the partial autocorrelation coefficients in Table 1. Both first- and second-order autocorrelations are consistently and statistically positive. For own-fund own-country flows, these autocorrelations are about $12 \%$, which is not economically very large, but given the number of data points is extremely significant (the standard error is much less than 1\%). It is interesting to note, however, that the own-fund owncountry autocorrelations are considerably higher (27\%-29\%) in the digital and buy/sell count flow indicators than in the raw flows themselves. This is because the scale, but not the direction, of dollar transactions, even for a given fund and given country jumps around considerably in the data. As a result of these 'outlier' datapoints, directional indictors appear more persistent.

\footnotetext{
${ }^{8}$ Recall that our country definition of each stock refers to the country of incorporation.
} 
The third point to make is that the persistence is greater for higher levels of aggregation across funds, countries or both. We might expect this because larger aggregations create greater scope for cross-persistence to emerge. For example, for the digital indicator across all countries, ownfund own-country first-order autocorrelation is $26.7 \%$, own-fund cross-country autocorrelation is $26.9 \%$, cross-fund own-country autocorrelation is $38.0 \%$ and cross-fund cross-country is $35.6 \%{ }^{9}$

\section{Results}

Before interpreting the regressions results, we note that the standard errors are simple OLS. Driving this choice is that we have very many data points, over 21 million, so that many variables appear extremely statistically significant, with t-statistics that range from 10 to 1,000 . Adjustments that are often made to OLS standard errors to account for cross-sectional or autocorrelations of the residuals are unlikely to reverse t-statistics of this magnitude, even in the presence of strong correlations. Indeed, here we have the presence of only weak contemporaneous correlation (see Figures 4 and 5), and, with the use of lagged variables to eliminate autocorrelation, we have very weak serial dependence. As a consequence, we report OLS standard errors, but interpret them conservatively. We take the informal view that a variable that cannot achieve a t-statistic of, say, 4 , with the power of 21 million observations is probably too small to matter, so that, as in many large sample studies, marginal statistical significance is immaterial.

The results of our decomposition of aggregate multi-fund, multi-country flows, $f_{i, k, t}$ are shown in Table 2. The correlation of aggregate flows is approximately, $40 \%$ with a standard deviation of approximately $0.4 \%$. This is about the same level of flow persistence found by Froot, O'Connell and Seasholes (2001) and Richards (2002) for international investors.

Table 2.1 then shows how the 0.40 total breaks down across the four different sources of flow persistence. Much as in the return literature, the vast size of the cross section (both across funds and countries) implies that much of the autocorrelation of total flows is driven by the cross components, rather than own flows. Indeed, Table 2.1 shows that own-fund own-country flows account for only about 0.027 , or about $7 \%$ of the overall total 0.40 . Own-fund cross-country flows account for another 0.019 , another $5 \%$ or so. So own-fund flows appear relatively

\footnotetext{
${ }^{9}$ Since we have many more funds than countries in our data, cross-fund own-country aggregations tend to be more highly aggregated than cross-country own-fund aggregations.
} 
unimportant in explaining total flow persistence. While there are more funds than countries, this is nevertheless a relatively small contribution from the cross-country effects.

The large contributions to total flows necessarily come from the two cross-fund components, and do so about equally from cross-fund own-country, and cross-fund cross-country components. These account for 0.219 and 0.140 , respectively, of the total 0.40 . The simple interpretation of this finding would be that the informed trader effects are not very important in explaining flow persistence; we should instead look to lags -- particularly across funds and countries -- in implementation and decision-making.

However, this conclusion would be naïve, since some portion of the cross effects might emerge under the informed trading hypothesis. The only way to find out is to examine the multivariate regression results from equation (6).

When we estimate equation (6), we do so in weekly as well as daily data, and for developed as well as emerging markets. These results are in Table 3, where there are several things to notice. First, it is clear that own-fund own-country persistence remains very powerful indeed. The firstorder correlations generally are in the range of the high 20 s to low $30 \mathrm{~s}$ (and t-statistics in the hundreds or thousands). The first-order autocorrelation at the daily frequency is $26.3 \%$. Second and third order partial autocorrelations show a similar pattern at $10.4 \%$ and $7.5 \%$, respectively. Under our null hypothesis, own-fund own-country persistence should be directly (negatively) linked to liquidity, and that appears to be the case in the data.

The same estimates for weekly data show a slightly higher first-order autocorrelation, at $30.4 \%$, but lower second and third order correlations. The weekly estimates are probably somewhat more reliable. Given that the flows happen around the world, their daily timing is harder to pin down. All these numbers continue to be of very high statistical significance.

In terms of the cross effects in Table 3, there are a number of interesting points to notice. First, by far the most important cross effect is the cross-fund, own-country coefficient. In daily data the first-order coefficient is approximately $8 \%$, with another $4 \%$ added by second- and third-order coefficients. In the weekly data, the cross-fund own-country coefficients come in slightly stronger, at $9 \%$ and $5 \%$, respectively. 
The other cross terms are far more mixed. The own-fund cross-country coefficients are not consistently positive. While the first-order daily coefficient is $2.2 \%$, the second-order coefficient is $-2.0 \%$. In the weekly data, the first-order coefficient is negative, at $-3.0 \%$. These results suggest that there is little own-fund cross-country persistence after accounting for own-fund owncountry persistence.

The absence of any effect also applies to cross-fund cross-country persistence. Here the coefficients in both daily and weekly data are small (at 1\%-4\%) and are measured relatively imprecisely, many not meeting even standard levels of statistical significance. Some of the lag coefficients are also negative.

Table 4 reports the same set of estimates on lagged flows, but this time including lagged owncountry equity returns (in dollars) as well as US returns. The motivation for including past owncountry returns is considerable previous evidence that institutional equity flows follow momentum strategies (i.e., trend chase), both in US domestic and international flow data. ${ }^{10}$ Most of the research looks at own returns, rather than cross returns. An important exception to this is Richards (2002). He finds that lagged US returns have important positive impacts on international investor flows into Asia stock markets. As a result of this evidence we try including US returns in addition to local market returns.

The estimates in Table 4 make two important, and striking points. The first is that the lagged flow coefficients are almost completely unchanged with the inclusion of lagged returns. All of the conclusions reached above in the absence of flows remain true when several lags of returns are present. Moreover, the point estimates are very close to being unchanged. Returns may be important, but their absence doesn't cloud any conclusions about flow persistence.

The second point is that lagged own-country equity returns are highly statistically significant, as suggested by the literature on momentum investing. For the 21 developed countries in our sample, there is no additional explanatory power added through lagged US returns.

\footnotetext{
${ }^{10}$ Cohen, Gompers, and Vuolteenaho (2001) find evidence that institutional investors chase only the permanent component of past returns. A temporary positive return is associated with future net sales, not purchases of stocks. Froot and Ramadorai (2001) find a somewhat similar result, that institutional investors purchases of cross-border stocks follow a measure of permanent return derived from closed-end fund prices, and tend flow again past temporary returns by this measure.
} 
Table 5 provides estimates of equation (7). This specification is the same as that in Table 4, except that we allow own-fund own-country persistence to vary by country. This may help account for differences in liquidity across countries. We include lagged returns in Table 5, as well, though, as we just saw, they result in only very minor impacts on lagged flow coefficients. Because there are now 21 own-fund own-country coefficients (one for each country), we report in the table the average of these coefficients.

The estimates in Table 5 show that many countries have less first-order own-fund own-country persistence than reported for all countries combined. However, the effect appears to be more in the timing rather than in the magnitude of the own-fund own-country autocorrelation. While the first-order own coefficients fall, the second- and third-order coefficients rise by approximately offsetting amounts. The sum of the lagged coefficients in Table 5 (approximately 45\%) remains essentially unchanged from the comparable weekly estimates in Table 4.

\section{Conclusions}

This paper has examined the persistence of institutional investor flows into a set of 21 developed countries. We confirm previous findings that the portfolio flows of international investors are highly persistent, with daily autocorrelations of about $40 \%$. We then find that, by a simple additive decomposition, almost $90 \%$ of this is attributable to cross-fund components of persistence, with the cross-fund cross-country component being the single most important piece. Own-fund own-country persistence (which comes only from the trace of non-contemporaneous flow covariance matrix) is relatively unimportant, as might be expected from a large cross section of flow data.

How large should these various own and cross components be relative to one another? To answer this, we refer to what we call the 'informed trader hypothesis,' which says that traders with real or perceived information about a country or a stock, will get into their positions slowly, as long as liquidity is less than perfect. This behavior can explain own- as well as cross-effects and gives us a null hypothesis to determine their relative sizes.

When we implement our test of this, conditioning on the magnitude of own-fund own-country persistence, the nature of the persistence decomposition changes importantly. The own-fund owncountry components are few in number, but explain much of what is happening in the cross 
section. Using this metric, approximately $75 \%$ of the persistence is attributable to own-fund owncountry persistence, i.e., the informed trader model. Of the remaining cross effects, the only one of material importance is that of cross-fund own-country persistence, accounting for most of the remaining $25 \%$ of total persistence. This component cannot be explained by individual funds moving slowly into individual investments. Rather, it must be the result of some form of delay that operates across funds for a given country, not within funds across countries or across funds across countries.

Two plausible stories strike us as being consistent with these findings. The first is that there are meaningful implementation and decision-making lags across funds. Information may reach these funds at the same time, but those who act upon it do not do so simultaneously. There may be differences in the way investment decisions are made, or there may be other, fund-specific aspects of the investment process that result in information being expressed in trades at different time.

Another plausible story is that managers follow each other's trades after they have the chance to observe them. This may be very sensible behavior. It could be fund trades carry positive information about future returns. We don't study that here, though previous studies (e.g., Froot, O'Connell, and Seasholes, 2001) have found this to be the case. It could also be some funds follow others, not because they are chasing returns, but because other peer funds' allocations act as benchmarks (see Chow 1995). Staying near the allocation of its peers would reduce a fund's peer risk. Either of these stories could be told as a herding story or as a rational decision-making story.

Finally, our results stand somewhat in contrast with studies that focus on the composition of stock index return persistence rather than flow persistence. In returns, noncontemporaneous index autocorrelations are driven exclusively by cross-stock effects. There are two points to make about this. First, it may be that intermediaries prevent evidence of predictable own-stock persistence from emerging, so that the informed trading hypothesis cannot be tested well using return data. Second, it may be that there are also important cross-stock effects in flow data. In this paper, we disaggregate only to the country investment level, and we leave such questions about individual stock flow behavior for future research. 


\section{References}

Brennan, M. and H. Cao, "International portfolio investment flows," Journal of Finance 52, 1851-1880, 1997.

Choe, H., B.C. Kho, and R. Stulz, "Do foreign investors destabilize stock markets? The Korean experience in 1997," Journal of Financial Economics 54, 227-264, 1999.

Choe, H., B.C. Kho, and R. Stulz, "Do domestic investors have more valuable information about individual stocks than foreign investors?," NBER working paper no. W8073, 2001.

Chow, G., "Portfolio selection based on return, risk, and relative performance," Financial Analysts Journal, March-April, 54-60, 1995.

Cohen, R., P. Gompers, and T. Vuolteenaho, "Who underreacts to cashflow news? Evidence from trading between individuals and institutions," manuscript, Harvard University, 2001.

Froot, K., "Consistent covariance matrix estimation with cross-sectional dependence and heteroskedasticity in cross-sectional financial data," Journal of Financial and Quantitative Analysis 24, 333-355, 1989.

Froot, K., P. O'Connell, and M. Seasholes, "The portfolio flows of international investors," Journal of Financial Economics 59, 151-193, 2001.

Froot, K., and A. Perold, "New trading practices and short-run market efficiency," Journal of Futures Markets 15, 731-766, October 1995.

Froot, K., and T. Ramadorai, "The information content of international portfolio flows," NBER working paper no. 8472, September 2001.

Goetzmann, W., M. Massa, and G. Rouwenhorst, "Behavioral factors in mutual fund flows," Yale ICF working paper no. 00-14, 1999.

Grinblatt, M., and M. Keloharju, "The investment behavior and performance of various investortypes: A study of Finland's unique data set," Journal of Financial Economics 55, 43-67, 2000.

Grinblatt, M., S. Titman, and R. Wermers, "Momentum investment strategies, portfolio performance, and herding: A study of mutual fund behavior," American Economic Review 85, 1088-1105, 1995.

Jegadeesh, N. and S. Titman, "Returns to buying winners and selling losers: implications for stock market efficiency," Journal of Finance 48, 65-91, 1993.

Kaminsky, G., R. Lyons, and S. Schmulker, "Managers, investors, and crises: mutual fund strategies in emerging markets," World Bank, 2000. 
Kim, W., and S.J. Wei, "Foreign portfolio investors before and during a crisis," Journal of International Economics 56, 77-96, 2000.

Kyle, A., "Continuous auctions and insider trading, " Econometrica 53, 1315-1336, 1985.

Kyle, A., and W. Xoing, "Contagion as a wealth effect," Journal of Finance 55, 4, 1401-1443, 2001.

Lakonishok, J., A. Shleifer, and R. Vishny, "The impact of institutional trading on stock prices," Journal of Financial Economics 32, 23-43, 1992.

Lo, A. and C. MacKinlay, "Stock market prices do not follow random walks: Evidence from a simple specification test," Review of Financial Studies 1, 41-66, 1988.

Nofsinger, J., and R. Sias, "Herding and feedback trading by institutional and individual investors," Journal of Finance 54, 2263-2295, 1999.

Richards, A., "Big fish in small ponds: the momentum investing and price impact of foreign investors in Asian emerging equity markets," draft discussion paper, Reserve Bank of Australia, 2002.

Rouwenhorst, G., “International momentum strategies, ” Journal of Finance 53, 1998.

Seasholes, M., "Smart foreign traders in emerging markets," University of California Berkeley, 2000 .

Sias, R., "Price pressure and the role of institutional investors in closed-end funds," Journal of Financial Research 20, 211-229, 1997.

VanRoyen, A.S. and S. Page, "The multiple dimensions of asset allocation: countries, sectors, or factors?," State Street Associates, 2002.

Wermers, R., "Mutual fund herding and the impact on stock prices," Journal of Finance 54, 581$622,1999$.

Wermers, R., "Mutual fund performance: An empirical decomposition into stock-picking talent, style, transaction costs, and expenses," Journal of Finance 55, 1655-1695. 
Figure 1: $\Gamma$, The Fund/Country Non-contemporaneous Covariance Matrix

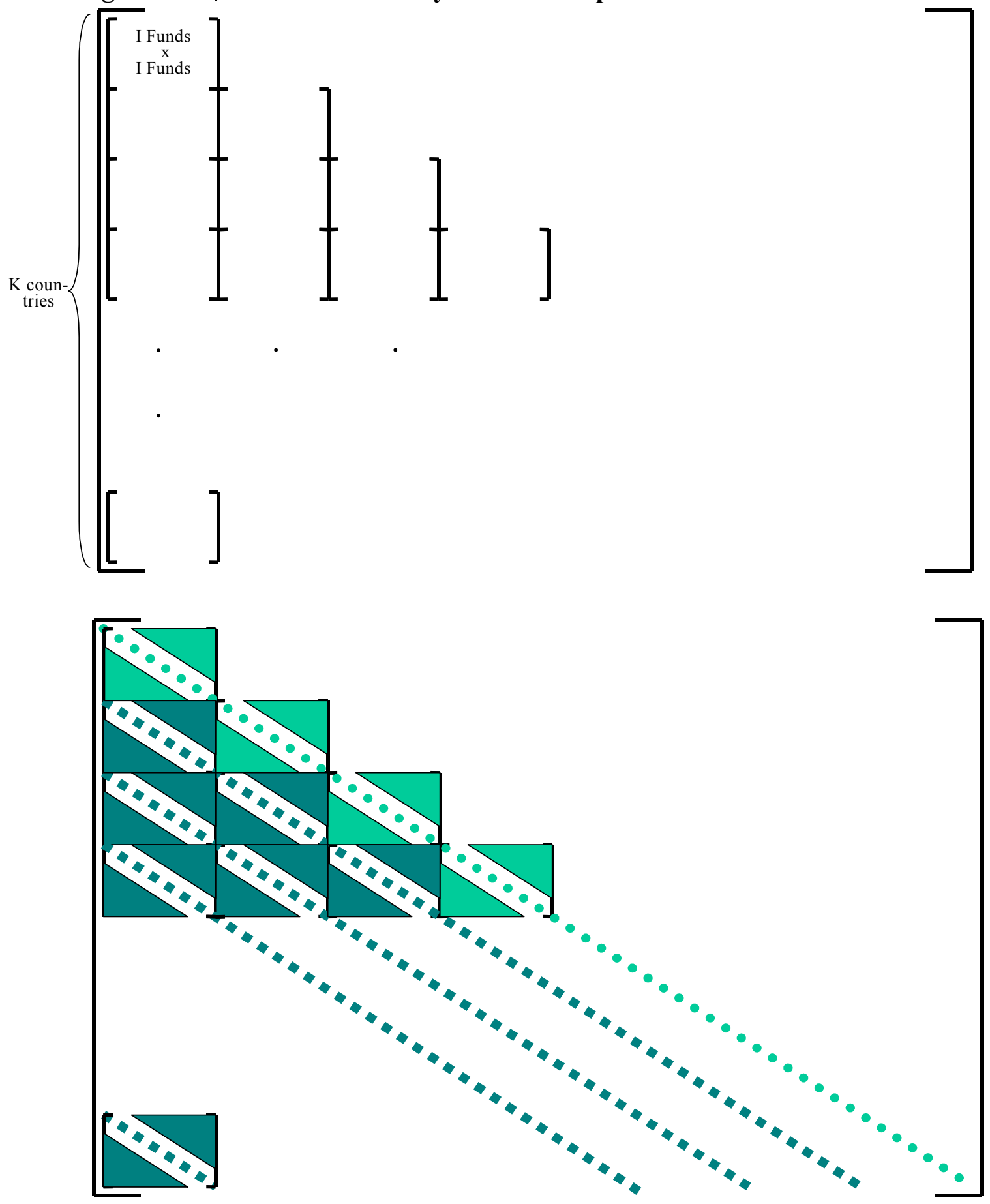

- Own-fund own-country covariance, $\alpha_{\mathrm{oo}}$

..... Own-fund cross-country covariance, $\alpha_{o c}$

Cross-fund own-country covariance, $\alpha_{\text {co }}$

Cross-fund cross-country covariance, $\alpha_{\mathrm{cc}}$ 


\section{Figure 2: Trading by Date of Individual Funds}

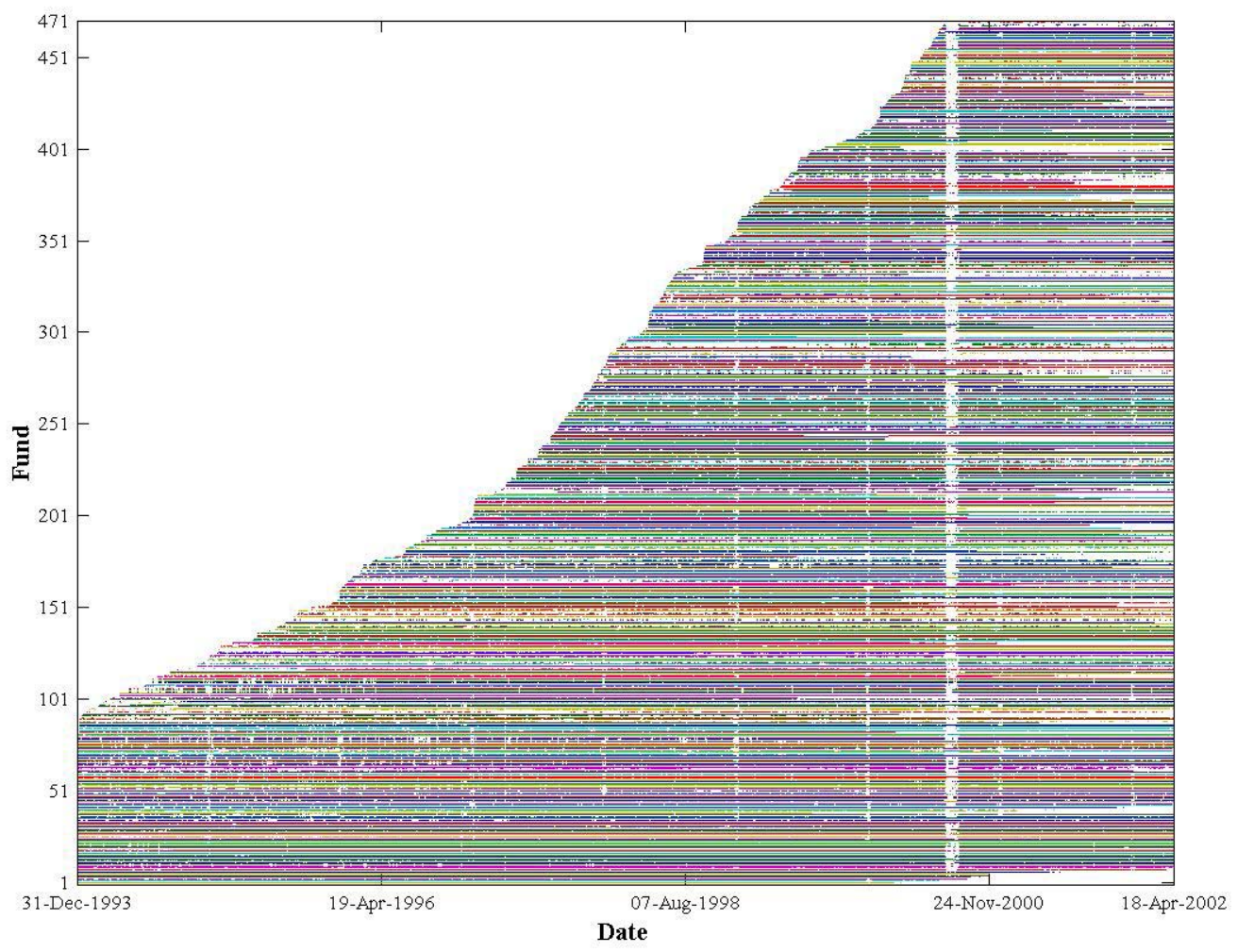


Figure 3: Number of Trades by Individual Funds for Each Country (relative to individual fund total number of trades over all countries)

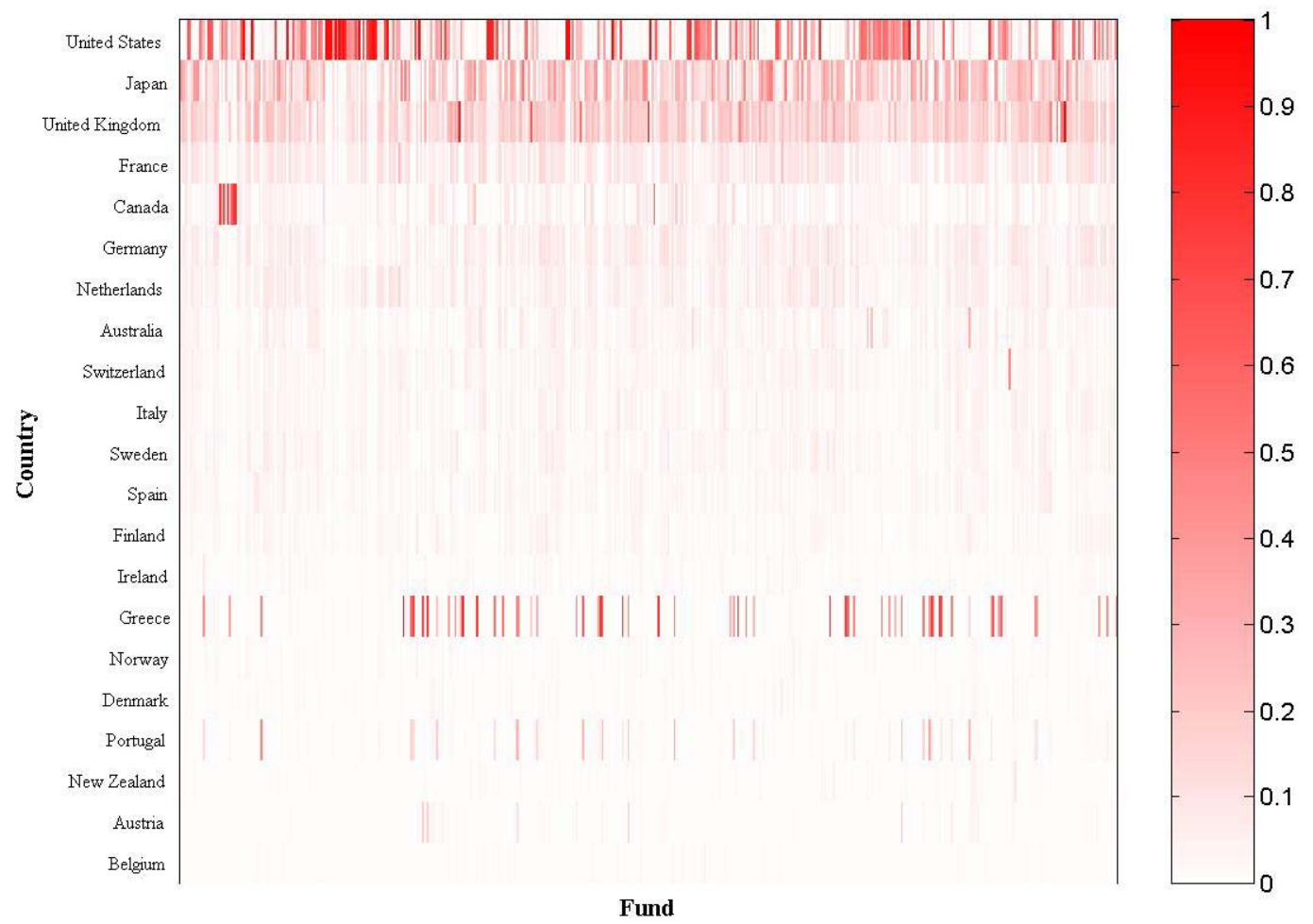


Figure 4: Weekly Correlation of Flows Across Countries

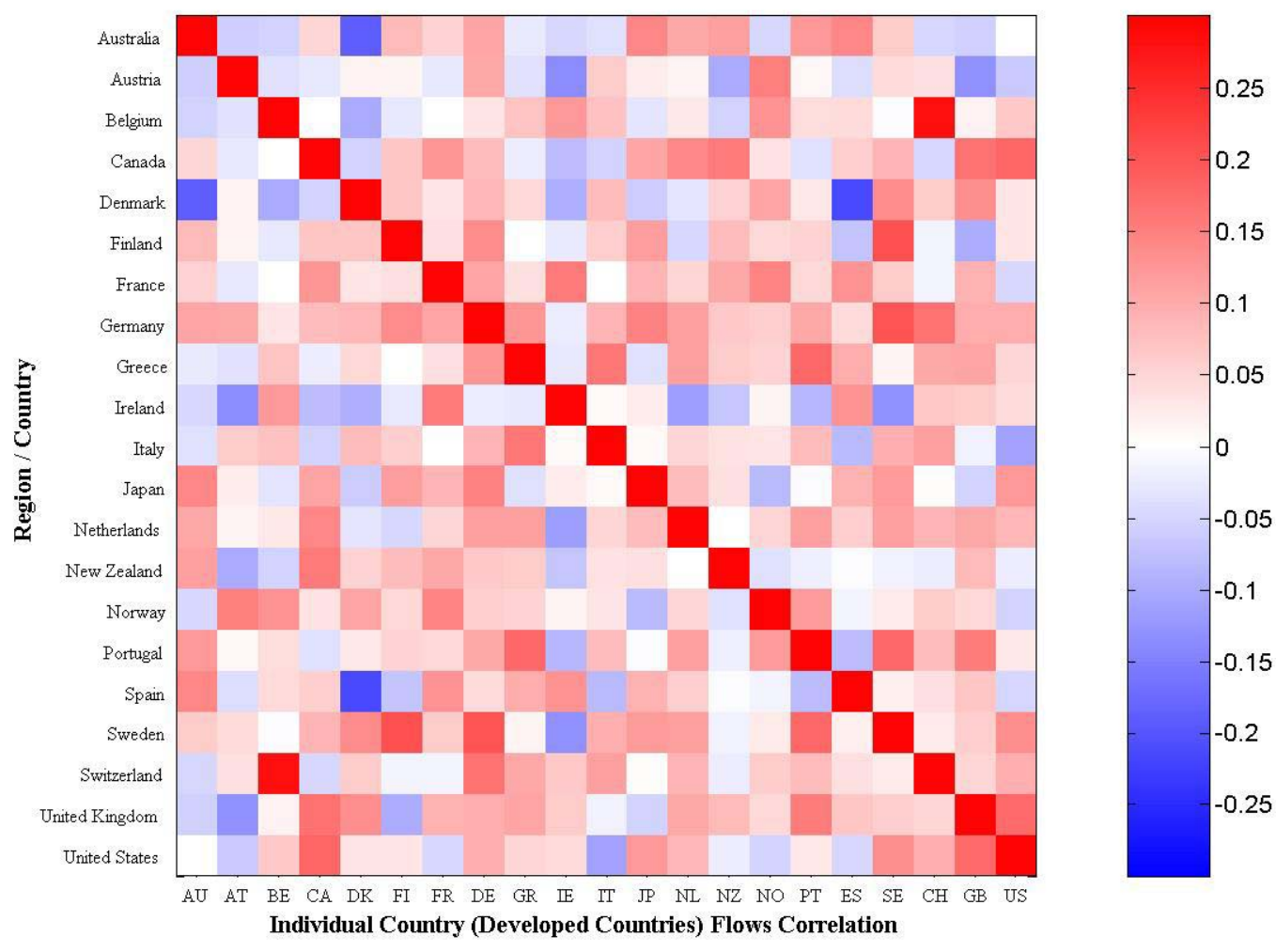


Figure 5: Weekly Correlations of Flows Across Regions

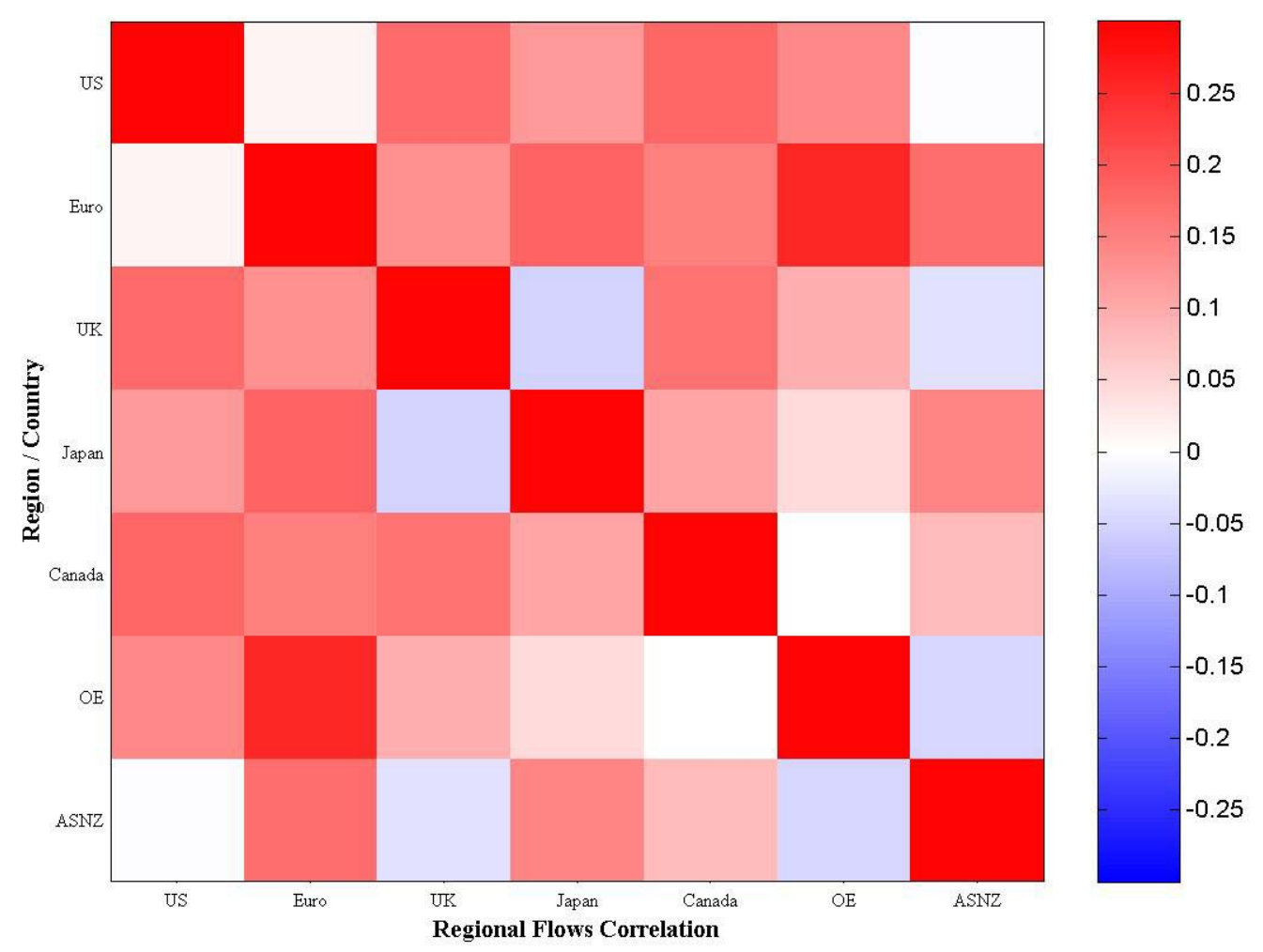

Regions include Euro (Austria, Belgium, Germany, Spain, Finland, France, Ireland, Italy, Netherlands, Portugal, Greece), OE ("Other European" -- Denmark, Sweden, Norway, Switzerland), ASNZ (Australia, New Zealand). 


\section{Table 1.1: Descriptive Statistics for Net U.S. Dollar Flows}

The table provides the summary data on the net flows of institutional investors, across funds and countries. The flows cover 21 developed markets. In the first column below we report for fund $\mathrm{i}$ and country $\mathrm{k}$ at time $\mathrm{t}, F_{i k t}$, the net U.S. dollar net flow. The second column sums the net dollar flows over all funds $\mathrm{j}$ not equal to $\mathrm{i}$ for a given country $\mathrm{k}$ at each time period. The third variable gives, for fund $\mathrm{i}$, the sum of all of its flows into countries other than k. Finally, the last term is the sum of flows over all country and fund pairs that do not include fund $\mathrm{i}$ and country $\mathrm{k}$. The summary data we report include the mean, $\mu$, the standard deviation, $\sigma$, and the first and second order autocorrelations, $\rho_{1}$ and $\rho_{2}$, stacking the data across $i$ and $k$. The first and second autocorrelations are calculated by regressing the variable in question on two lags of itself for each $(\mathrm{i}, \mathrm{k})$ pair and then averaging across all active funds in country $\mathrm{k}$.

\begin{tabular}{rrrrc}
\hline & $F_{i, k, t}$ & $\sum_{j \neq i} F_{j, k, t-\tau}$ & $\sum_{l \neq k} F_{i, l, t-\tau}$ & $\sum_{j \neq i} \sum_{l \neq k} F_{j, l, t-\tau}$ \\
$\mu^{*}$ & 6.40 & $1,988.56$ & 128.08 & $39,771.22$ \\
$\sigma^{*}$ & $1,198.84$ & $30,696.54$ & 6042.06 & $160,352.92$ \\
$N$ & $12,728,330$ & $12,728,330$ & $12,728,330$ & $12,728,330$ \\
$\rho_{1}$ & 0.1208 & 0.2514 & 0.1813 & 0.3089 \\
$\rho_{2}$ & 0.0291 & 0.0737 & 0.0313 & 0.0799 \\
\hline
\end{tabular}

* Note that the mean and standard deviations are in thousands of U.S. Dollars. 


\section{Table 1.2: Descriptive Statistics for Digital Signal}

The table provides the summary data on the sign or digital signal of net flows of institutional investors, across funds and countries where a net inflow is represented as a +1 , a net outflow as -1 and no flow is 0 . The flows cover 21 developed markets. In the first column below we report for fund $\mathrm{i}$ and country $\mathrm{k}$ at time $\mathrm{t}, f_{i k t}^{d}$, the net U.S. Dollar flow signal for country k. The second column sums the net dollar flows signals over all funds $\mathrm{j}$ not equal to $\mathrm{i}$ for a given country $\mathrm{k}$ at each time period. The third variable gives, for fund $\mathrm{i}$, the sum of all of its flow signals into countries other than k. Finally, the last term is the sum of flow signals over all country and fund pairs that do not include fund $\mathrm{i}$ and country $\mathrm{k}$. The summary data we report include the mean, $\mu$, the standard deviation, $\sigma$, and the first and second order autocorrelations, $\rho_{1}$ and $\rho_{2}$, stacking the data across $\mathrm{i}$ and $\mathrm{k}$. The first and second autocorrelations are calculated by regressing the variable in question on two lags of itself for each $(\mathrm{i}, \mathrm{k})$ pair and then averaging across all active funds in country.

\begin{tabular}{rrrrr}
\hline & $f_{i, k, t}^{d}$ & $\sum_{j \neq i} f_{j, k, t}^{d}$ & $\sum_{l \neq k} f_{i, l, t}^{d}$ & $\sum_{j \neq i} \sum_{l \neq k} f_{j, l, t}^{d}$ \\
$\mu$ & & & & \\
$\sigma$ & 0.0049 & 1.3128 & 0.0974 & 26.2569 \\
$\rho_{1}$ & 0.3380 & 16.1972 & 1.9009 & 83.0693 \\
$\rho_{2}$ & 0.2669 & 0.3804 & 0.2693 & 0.3559 \\
\hline
\end{tabular}

\section{Table 1.3: Descriptive Statistics for the Buy-Sell Ratio}

The table provides the summary data on the buy-sell ratio, the ratio of the number of buy transactions minus the number of sell transactions as a percentage of total buy and sell transactions, of net flows of institutional investors, across funds and countries. The flows cover 21 developed markets. In the first column below we report for fund $\mathrm{i}$ and country $\mathrm{k}$ at time $\mathrm{t}, f^{c}{ }_{i k t}$, the buy-sell ratio for country $\mathrm{k}$. The second column sums the buy-sell ratio over all funds $\mathrm{j}$ not equal to $\mathrm{i}$ for a given country $\mathrm{k}$ at each time period. The third variable gives, for fund $\mathrm{i}$, the sum of all of its buy-sell ratios into countries other than k. Finally, the last term is the sum of buy-sell ratios over all country and fund pairs that do not include fund i and country $\mathrm{k}$. The summary data we report include the mean, $\mu$, the standard deviation, $\sigma$, and the first and second order autocorrelations, $\rho_{1}$ and $\rho_{2}$, stacking the data across $i$ and $\mathrm{k}$. The first and second autocorrelations are calculated by regressing the variable in question on two lags of itself for each (i,k) pair and then averaging across all active funds in country $\mathrm{k}$.

\begin{tabular}{rrrrr}
\hline & $f_{i, k, t}^{c}$ & $\sum_{j \neq i} f_{j, k, t}^{c}$ & $\sum_{l \neq k} f_{i, l, t}^{c}$ & $\sum_{j \neq i} \sum_{l \neq k} f_{j, l, t}^{c}$ \\
$\mu$ & & & & \\
$\sigma$ & 0.0044 & 1.1741 & 0.0880 & 23.4816 \\
$\rho_{1}$ & 0.3033 & 15.1090 & 1.7771 & 78.4616 \\
$\rho_{2}$ & 0.2887 & 0.3957 & 0.3069 & 0.4094 \\
\hline
\end{tabular}




\section{Table 2.1: Covariance Decomposition}

This table reports the decomposition of total flow autocorrelation into four components: own lag, lagged cross-fund own-country signals, lagged own-fund cross-country signals and cross-fund cross-country signals. The decomposition is based on the equation.

$$
\alpha(\tau)=\left(\alpha_{o o}(\tau)+\alpha_{o c}(\tau)+\alpha_{c o}(\tau)+\alpha_{c c}(\tau)\right)
$$

We use digital signals of underlying net flows for this decomposition. The results are obtained by regressing a single lag of each of the four component variables on , $f^{d}{ }_{k t}$, the net U.S. Dollar flow signal for country $\mathrm{k}$. We also report the composition in terms of percentages.

\begin{tabular}{|c|c|c|c|c|c|}
\hline & & $\alpha_{o o}(\tau)$ & $\alpha_{c o}(\tau)$ & $\alpha_{o c}(\tau)$ & $\alpha_{c c}(\tau)$ \\
\hline $1^{\text {st }}$ order & 40.4722 & 2.7266 & 21.9617 & 1.9247 & $13.85 \mathrm{~s}$ \\
\hline Percentage & & $6.74 \%$ & $54.26 \%$ & $4.76 \%$ & $34.24 \%$ \\
\hline
\end{tabular}




\section{Table 2.2: Autoregressive Behavior of Digital Equity Flow Signals}

The table reports the first, second and third order autoregressive coefficient for the digital signals where a net inflow is represented as a +1 , a net outflow as -1 and no flow is 0 . Each column represents the results for the autoregression. The first column reports the results for the sum of total signals across countries and funds. Columns 2 to 5 give the results for each of the four digital variables discussed in Table 1.2. The equation being estimated in all cases is the following.

$$
f^{d}=c+a(L) f^{d}+\varepsilon_{t},
$$

The subscripts on the autoregressive coefficients indicate the flow variable used in the autoregression; $\alpha_{\mathrm{oo}}$ is the coefficient for the regression of own-fund, own-country digital signals, $\alpha_{\text {co }}$ is the coefficient for cross-fund own-country signals, $\alpha_{\mathrm{oc}}$ is for own-fund cross-country signals, and $\alpha_{\mathrm{cc}}$ is for cross-fund crosscountry signals. Standard errors are reported in parentheses.

\begin{tabular}{|c|c|c|c|c|c|}
\hline & $f_{t}$ & $a_{o o}(L)$ & $a_{c o}(L)$ & $a_{o c}(l)$ & $a_{c c}(L)$ \\
\hline \multirow[t]{2}{*}{$1^{\text {st }}$ order } & 0.3466 & 0.2649 & 0.2985 & 0.1224 & 0.0961 \\
\hline & $(0.0047)$ & $(0.0003)$ & $(0.0023)$ & $(0.0011)$ & $(0.0088)$ \\
\hline \multirow[t]{2}{*}{$2^{\text {nd }}$ order } & 0.0733 & 0.1044 & 0.1310 & 0.0237 & 0.0014 \\
\hline & $(0.0049)$ & $(0.0003)$ & $(0.0024)$ & $(0.0011)$ & $(0.0093)$ \\
\hline \multirow[t]{2}{*}{$3^{\text {rd }}$ order } & 0.1236 & 0.0753 & 0.1062 & 0.0237 & 0.0585 \\
\hline & $(0.0047)$ & $(0.0003)$ & $(0.0023)$ & $(0.0011)$ & $(0.0088)$ \\
\hline$R^{2}$ & 0.2927 & 0.1176 & 0.0037 & 0.0019 & 0.0002 \\
\hline$S E$ & 14.8410 & 0.3170 & 0.3369 & 0.2934 & 0.3375 \\
\hline$N$ & 45,465 & $12,728,331$ & $12,728,331$ & $12,728,331$ & $12,728,331$ \\
\hline
\end{tabular}




\section{Table 3: Persistence of Institutional Investor's Flows}

This table shows the results of a regression of own-fund own-country digital signals from underlying flow data on its own lags, lagged cross-fund own-country signals, lagged own-fund cross-country signals and cross-fund cross-country signals. The equation estimated is the following.

$$
f_{i, k, t}=c+a_{o o}(L) f_{i, k, t-1}+a_{c o}(L) \sum_{j \neq i} f_{j, k, t-1}+a_{o c}(L) \sum_{l \neq k} f_{i, l, t-1}+a_{c c}(L) \sum_{j \neq i} \sum_{l \neq k} f_{j, l, t-1}+\varepsilon_{i, k, t}
$$

These results are for the set of 21 different developed country equity markets in our sample. Results are reported for both the daily and weekly frequency. Standard errors are reported in parentheses.

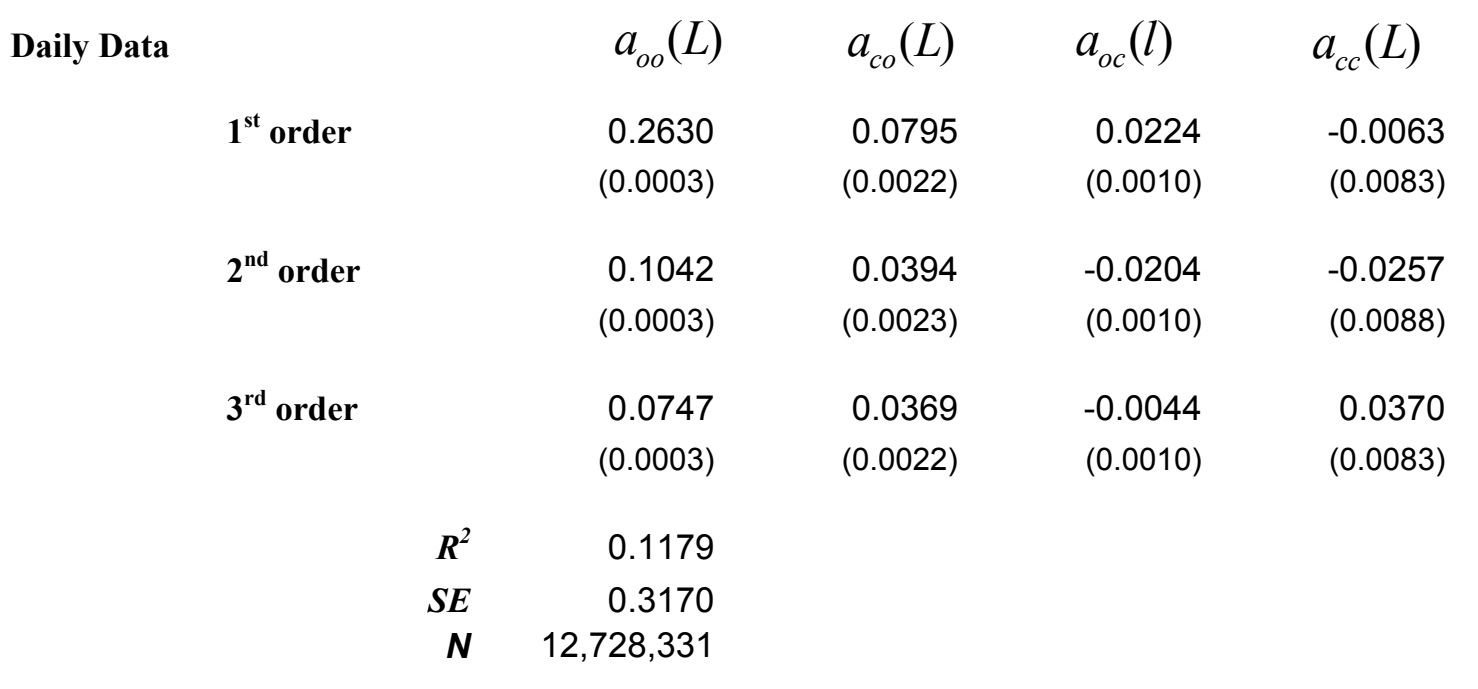

\begin{tabular}{|c|c|c|c|c|}
\hline \multicolumn{5}{|l|}{ Weekly Data } \\
\hline & $a_{o o}(L)$ & $a_{c o}(L)$ & $a_{o c}(l)$ & $a_{c c}(L)$ \\
\hline \multirow[t]{2}{*}{$1^{\text {st }}$ order } & 0.3040 & 0.0968 & -0.0299 & -0.0032 \\
\hline & $(0.0006)$ & $(0.0045)$ & $(0.0023)$ & $(0.0171)$ \\
\hline \multirow[t]{2}{*}{$2^{\text {nd }}$ order } & 0.0575 & 0.0506 & 0.0217 & -0.0242 \\
\hline & $(0.0007)$ & $(0.0049)$ & $(0.0023)$ & $(0.0181)$ \\
\hline \multirow[t]{2}{*}{$3^{\text {rd }}$ order } & 0.0530 & 0.0536 & 0.0335 & 0.0248 \\
\hline & $(0.0006)$ & $(0.0045)$ & $(0.0022)$ & $(0.0170)$ \\
\hline$R^{2}$ & 0.1213 & & & \\
\hline se of regression & 0.9785 & & & \\
\hline$N$ & $2,541,504$ & & & \\
\hline
\end{tabular}




\section{Table 4: Persistence of Institutional Investor's Flows Including Returns}

This table shows the results of a regression of own-fund own-country digital signals from underlying net flows of institutional investors on its own lags, cross-fund own-country signals, own-fund cross-country signals, cross-fund cross-country signals, own-country returns and returns in the U.S. market as the proxy for cross-country returns. The equation estimated is the following.

$f_{i, k, t}=c+a_{o o}(L) f_{i, k, t-1}+a_{c o}(L) \sum_{j \neq i} f_{j, k, t-1}+a_{o c}(L) \sum_{l \neq k} f_{i, l, t-1}+a_{c c}(L) \sum_{j \neq i} \sum_{l \neq k} f_{j, l, t-1}+b_{o}(L) r_{i, t-1}+b_{c}(L) r_{j, t-1}+\varepsilon_{i, k, t}$

These results are for the set of 21 different developed country equity markets in our sample. Results are reported for both the daily and weekly frequency. Standard errors are reported in parentheses.

\begin{tabular}{|c|c|c|c|c|c|c|c|}
\hline Daily Data & & $a_{o o}(L)$ & $a_{c o}(L)$ & $a_{o c}(L)$ & $a_{c c}(L)$ & $b_{o}(L)$ & $b_{c}(L)$ \\
\hline \multirow[t]{2}{*}{$1^{\text {st }}$ order } & & 0.2630 & 0.0793 & 0.0224 & 0.0007 & 0.1326 & 0.1216 \\
\hline & & $(0.0003)$ & $(0.0022)$ & $(0.0010)$ & $(0.0084)$ & $(0.0065)$ & $(0.0081)$ \\
\hline \multirow[t]{2}{*}{$2^{\text {nd }}$ order } & & 0.1042 & 0.0388 & -0.0204 & -0.0233 & 0.0183 & 0.0065 \\
\hline & & $(0.0003)$ & $(0.0023)$ & $(0.0010)$ & $(0.0089)$ & $(0.0065)$ & $(0.0085)$ \\
\hline \multirow[t]{5}{*}{$3^{\text {rd }}$ order } & & 0.0746 & 0.0368 & -0.0044 & 0.0400 & 0.0212 & -0.0475 \\
\hline & & $(0.0003)$ & $(0.0022)$ & $(0.0010)$ & $(0.0084)$ & $(0.0063)$ & $(0.0085)$ \\
\hline & $R^{2}$ & 0.1180 & & & & & \\
\hline & $S E$ & 0.3170 & & & & & \\
\hline & $N$ & $12,728,331$ & & & & & \\
\hline \multicolumn{8}{|c|}{ Weekly Data } \\
\hline & & $a_{o o}(L)$ & $a_{c o}(L)$ & $a_{o c}(L)$ & $a_{c c}(L)$ & $b_{o}(L)$ & $b_{c}(L)$ \\
\hline \multirow[t]{2}{*}{$1^{\text {st }}$ order } & & 0.3040 & 0.0950 & -0.0298 & 0.0009 & 0.1332 & -0.0874 \\
\hline & & $(0.0006)$ & $(0.0045)$ & $(0.0023)$ & $(0.0172)$ & $(0.0209)$ & $(0.0287)$ \\
\hline \multirow[t]{2}{*}{$2^{\text {nd }}$ order } & & 0.0575 & 0.0501 & 0.0217 & -0.0136 & 0.0631 & -0.1789 \\
\hline & & $(0.0007)$ & $(0.0049)$ & $(0.0023)$ & $(0.0182)$ & $(0.0210)$ & $(0.0290)$ \\
\hline \multirow[t]{5}{*}{$3^{\text {rd }}$ order } & & 0.0530 & 0.0529 & 0.0334 & 0.0160 & 0.0633 & 0.0773 \\
\hline & & $(0.0006)$ & $(0.0045)$ & $(0.0022)$ & $(0.0171)$ & $(0.0209)$ & $(0.0287)$ \\
\hline & $R^{2}$ & 0.1213 & & & & & \\
\hline & $S E$ & 0.9881 & & & & & \\
\hline & $N$ & $2,541,504$ & & & & & \\
\hline
\end{tabular}




\section{Table 5: Persistence With Country Specific Coefficients}

This table shows the results of a regression of weekly own-fund own-country digital signals from underlying net flows of institutional investors on its own lags, cross-fund own-country signals, own-fund cross-country signals, cross-fund cross-country signals, own-country returns and returns in the U.S. market as the proxy for cross-country returns. This specification includes separate own-fund own-country autoregressive coefficients for each market, $k$. The equation estimated is the following.

$$
\begin{aligned}
f_{i, k, t}= & c_{i, k}+a_{o o ; k}(L) f_{i, k, t-1}+a_{c o}(L) \sum_{j \neq i} f_{j, k, t-1}+a_{o c}(L) \sum_{l \neq k} f_{i, l, t-1}+a_{c c}(L) \sum_{j \neq i} \sum_{l \neq k} f_{j, l, t-1} \\
& +b_{o}(L) r_{i, t-1}+b_{c}(L) r_{j, t-1}+\varepsilon_{i, k, t}
\end{aligned}
$$

These results in the upper panel are for the 21 different developed country equity markets and the lower panel for the 15 different emerging country equity markets in our sample. Standard errors are reported in parentheses.

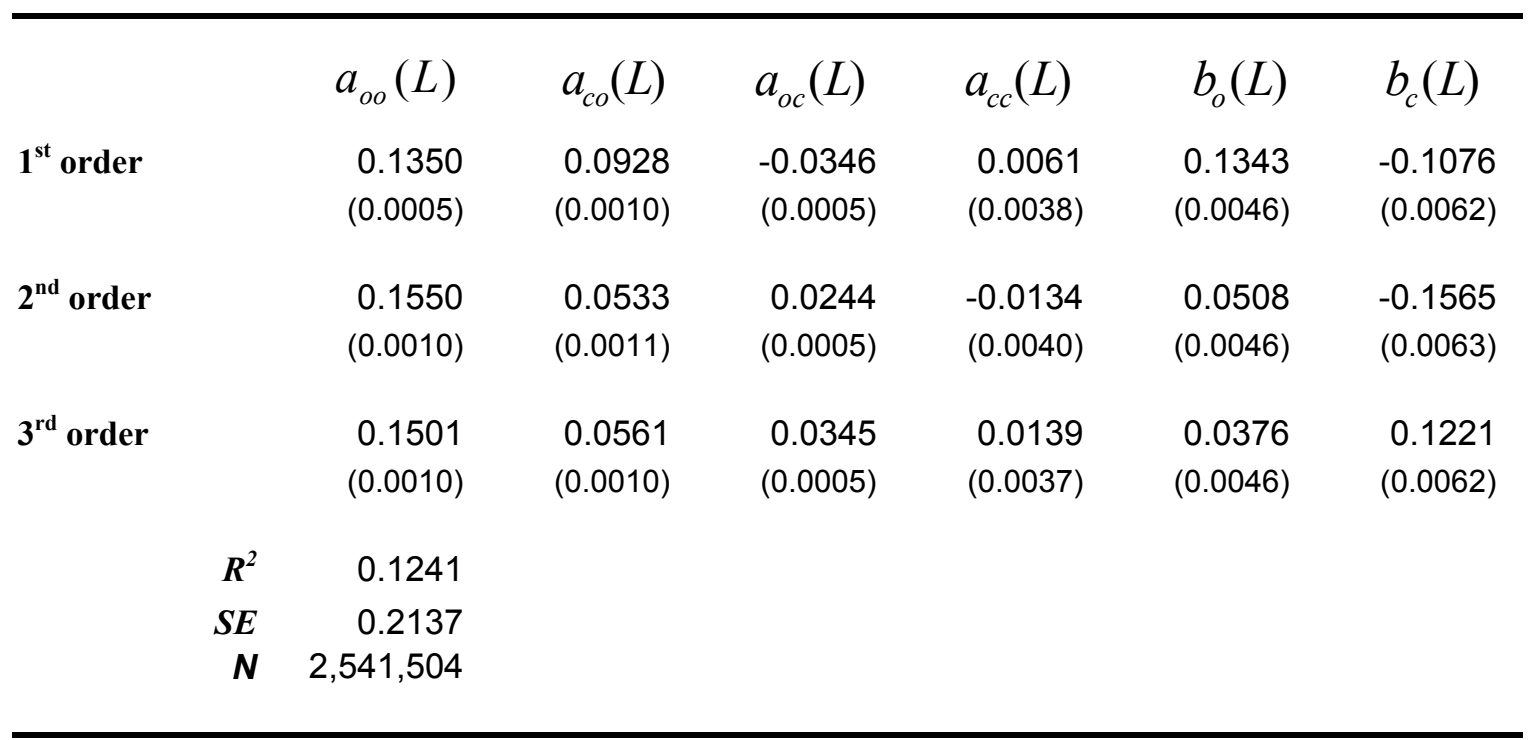

